\title{
Role of Macrophage Inflammatory Peptide-2 in Cerulein-Induced Acute Pancreatitis and Pancreatitis-Associated Lung Injury
}

\author{
Catherine M. Pastor, Laura Rubbia-Brandt, Antoine Hadengue, Martha Jordan, \\ Philippe Morel, and Jean Louis Frossard
}

Division of Gastroenterology and Hepatology (CMP, AH, MJ, JLF), Department of Clinical Pathology (LR-B), and Clinic of Digestive Surgery (PM), Geneva University Hospital, Geneva, Switzerland

\begin{abstract}
SUMMARY: Acute pancreatitis is an inflammatory process of variable severity, and leukocytes are thought to play a key role in the development of pancreatitis and pancreatitis-associated lung injury. The effects of mediators released by these inflammatory cells may induce tissue damage. The aim of our study was to evaluate the role of the chemokine, macrophage inflammatory protein-2 (MIP-2), in the pathogenesis of cerulein-induced pancreatitis and pancreatitis-associated lung injury. The severity of pancreatitis was measured by serum amylase, pancreatic edema, acinar cell necrosis, and myeloperoxidase activity. Lung injury was quantitated by evaluating lung microvascular permeability and lung myeloperoxidase activity. To determine the role of MIP-2 in the pathophysiology of the disease, anti-MIP-2 antibody was administered either 1 hour before or 2 hours after the start of cerulein administration. MIP-2 concentrations increased in serum, pancreas, and lung tissues in mice treated with cerulein. Anti-MIP-2 antibody administrated either before or after cerulein partially protected against pancreas and lung injury. These results show that MIP-2 plays a key role in the pathophysiology of acute pancreatitis and that MIP-2 blockade may improve the outcome of the disease. (Lab Invest 2003, 83:471-478).
\end{abstract}

$A$ cute pancreatitis is an inflammatory process that usually occurs in a normal organ (Frossard et al, 2002a; Steer, 1989; Steinberg and Tenner, 1994). The severity of the disease is variable, with a mortality ranging between $15 \%$ to $25 \%$ (Steer, 1989).

During acute pancreatitis, chemoattractant substances are responsible for the activation and the sequestration of leukocytes in inflamed tissues. Deleterious factors released by the sequestered leukocytes contribute to the pancreatic injury and the propagation of the disease to remote organs. During acute pancreatitis, macrophage inflammatory peptide- $1 \alpha$ (Gerard et al, 1997), and IL-8 (Gross et al, 1992) have been involved in the neutrophil activation and sequestration within pancreas and lungs.

Chemokines mediate the trafficking and the activation of leukocytes, lymphocytes, and macrophages. Human IL-8 is the most potent chemokine acting through the C-X-C chemokine receptor-2. Macrophage inflammatory protein-2 (MIP-2) is also a potent rodent chemokine, homologous to human GRO- $\beta$, which binds to the $\mathrm{C}-\mathrm{X}-\mathrm{C}$ chemokine receptor-2 (Baggiolini et al, 1997; Murphy et al, 2000). Additionally,

DOI: 10.1097/01.LAB.0000063928.91314.9F

Received December 3, 2002.

This work was supported by grants from the Swiss National Science Foundation (32.63618 to JLF and 32.63619 to CMP).

Address reprint requests to: Dr. Jean Louis Frossard, Division of Gastroenterology, Geneva University Hospital, 1211 Geneva 14, Switzerland. E-mail: jean-louis.frossard@hcuge.ch
MIP-2 may represent the mouse equivalent of human IL-8, but the full equivalence of MIP-2 and IL-8 is still speculative (Hang et al, 1999). The role of C-X-C chemokines (chemokines in which two cysteines$\mathrm{C}$-are separated by an amino acid-X) in acute pancreatitis has been recently studied (Frossard et al, 2002a, 2002b; Gerard et al, 1997; Grady et al, 1997). We then postulated that MIP-2 may play a key role in the pathogenesis of acute pancreatitis and, if this hypothesis was true, that pharmaceutical blockade of MIP-2 may decrease the severity of the disease.

To address this question, we induced an acute edematous form of acute pancreatitis by injecting supramaximal doses of cerulein, a pancreatic secretagogue, into mice. Cerulein-induced acute pancreatitis was associated with a significant increase in MIP-2 concentrations in serum, pancreas, and lungs. Interestingly, pretreatment and posttreatment with the anti-MIP-2 antibody decreased the severity of both pancreatitis and pancreatitis-associated lung injury.

\section{Results}

\section{Effects of Supramaximal Cerulein Stimulation on MIP-2 Concentrations}

Low MIP-2 concentrations were detected in serum $(19.9 \pm 5.4 \mathrm{pg} / \mathrm{ml})$ and in pancreas $(26.2 \pm 1.3 \mathrm{pg} / \mathrm{mg}$ protein) and lung (29.4 $\pm 4.5 \mathrm{pg} / \mathrm{mg}$ protein) tissues collected from control mice (Fig. 1). Administration of 10 ip injections of a supramaximal dosage of cerulein significantly increased the MIP-2 concentration in se- 


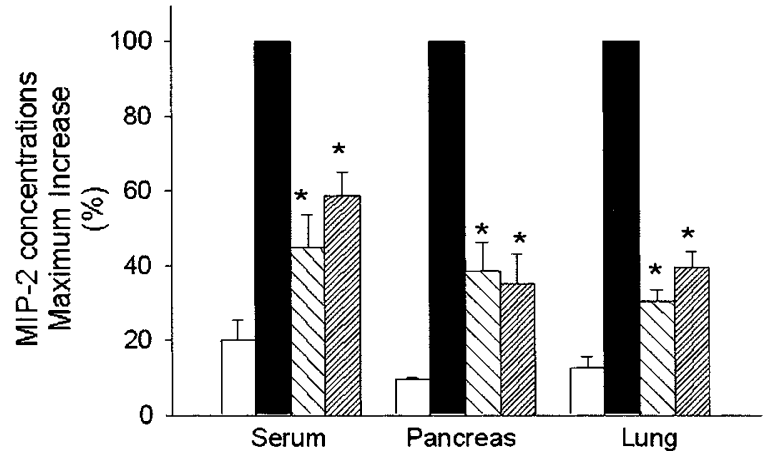

Figure 1.

Macrophage inflammatory protein-2 (MIP-2) concentrations in serum, pancreas, and lung are expressed as maximum increase (\%) to better delineate changes. Mice were injected with saline solution (open bars) or cerulein (solid bars, light-hatched bars, and dark-hatched bars). Light-hatched bars: pretreatment with anti-MIP-2 antibody; dark-hatched bars: posttreatment with antiMIP-2 antibody. Results are means \pm SEM. $n=10$ mice in each group for serum and $n=7$ for pancreas and lung homogenates. ${ }^{\star} p<0.05$ vs mice injected with cerulein and treated with rat nonspecific IgG.

rum $(109 \pm \mathrm{pg} / \mathrm{ml})$, pancreas $(191 \pm 32 \mathrm{pg} / \mathrm{mg}$ protein), and lung (243 $\pm 35 \mathrm{mg} / \mu \mathrm{g}$ protein) homogenates. Pretreatment with anti-MIP-2 antibody decreased MIP-2 levels. Similar reductions of MIP-2 concentrations in serum and homogenates were found with the posttreatment.

\section{Effects of Anti-MIP-2 Antibody on the Severity of Acute Pancreatitis}

Treatment with cerulein markedly increased serum amylase (Fig. 2A), pancreatic edema (Fig. 2B), and pancreatic necrosis (Figs. 2C and $3 \mathrm{~B}$ ). Pretreatment with anti-MIP-2 antibody protected against ceruleininduced acute pancreatitis. However, the protection was incomplete (Figs. 2 and 3). Interestingly, pancreatic edema at the time of autopsy was obviously decreased in mice pretreated with anti-MIP-2. Posttreatment also resulted in a significant protection against the development of acute pancreatitis, but to a lesser degree than the protection obtained with pretreatment (Fig. 2).

\section{Effects of Anti-MIP-2 Antibody on the Severity of Cerulein-Induced Acute Lung Injury}

Cerulein-induced acute pancreatitis was associated with lung injury, which is evidenced by an increase in lung edema (Fig. 4A) and pulmonary microvascular permeability to FITC-labeled albumin (Fig. 4B). The lung injury was partially decreased when anti-MIP2 antibody was injected before cerulein administration. Lung injury was also characterized by a marked thickening of the alveolar membrane (Figs. $4 \mathrm{C}$ and $3 \mathrm{G}$ ). The alveolar thickness induced by cerulein was significantly attenuated in mice pretreated with anti-MIP2 antibody (Figs. 4C and 3I). In the therapeutical approach, lung damage was also significantly decreased: edema (Fig. 4A) and lung alveolar thickness (Fig. 4C) decreased. However, lung permeability index (Fig. 4B) did not decrease significantly.
A

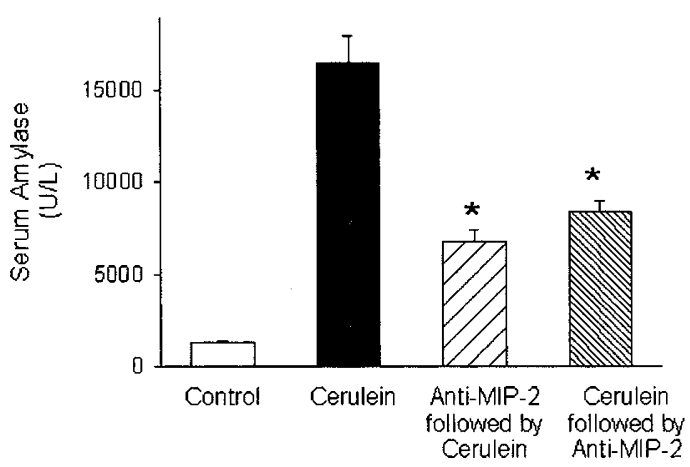

B



C



Figure 2.

Severity of acute pancreatitis: serum amylase (A), pancreatic water content (B), and pancreatic necrosis (C). Mice were injected with saline solution (open bars), cerulein and rat nonspecific IgG (solid bars), or anti-MIP-2 antibody and cerulein (light- and dark-hatched bars). Light-hatched bars: pretreatment with anti-MIP-2 antibody; dark-hatched bars: posttreatment with anti-MIP-2 antibody. Results are means \pm SEM. $n=10$ animals in each group. ${ }^{*} p<0.05$ vs mice injected with cerulein and treated with rat nonspecific lgG.

\section{Effects of Anti-MIP-2 Antibody on Leukocyte Infiltration in Pancreas and Lungs}

When mice were injected with cerulein, pancreas and lung myeloperoxidase (MPO) activities increased (Fig. $5 A)$, indicating that neutrophils were sequestered within both organs. Pretreatment and posttreatment with anti-MIP2 antibody significantly decreased MPO activities in mice injected with cerulein. Similar results were observed with the number of inflammatory cells in pancreas and lungs (Fig. 5B).

Effects of Anti-MIP-2 Antibody on TNF-a receptor I (TNF- $\alpha$ RI) Concentrations in Serum, Pancreas, and Lung

The increase in TNF- $\alpha \mathrm{RI}$ concentrations over time during cerulein-induced acute pancreatitis have pre- 

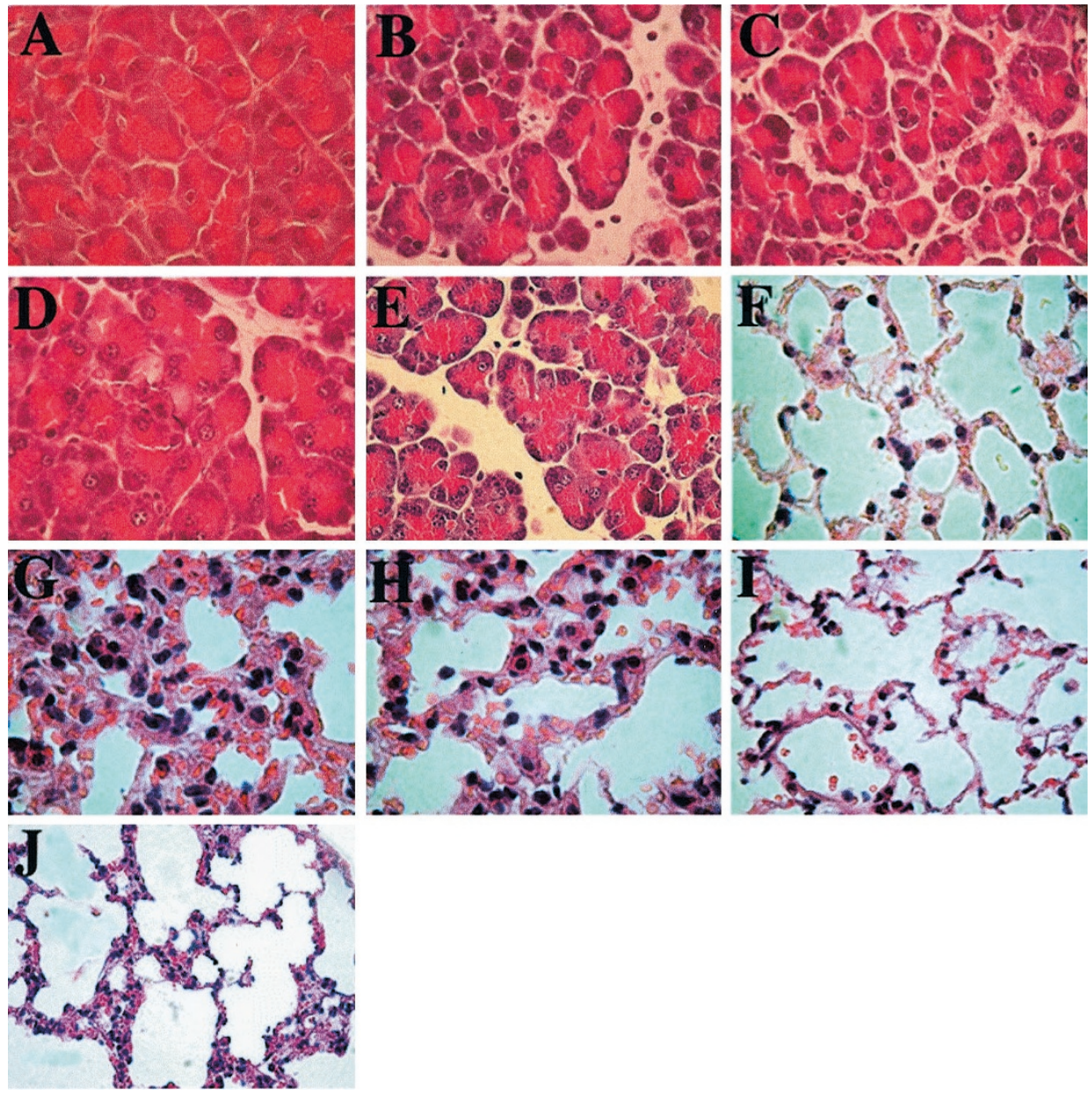

Figure 3.

Pancreas and lung injury. Representative sections of pancreas (upper panels) and lung (lower panels) stained with hematoxylin and eosin. Mice were injected with saline solution ( $A$ and $F$ ) or cerulein ( $B$ to $E$ and $G$ to J). Mice were injected with rat nonspecific IgG (C and H) or anti-MIP-2 antibody before cerulein (D and I) or after cerulein ( $E$ and $J)$. These results are representative of at least five animals.

viously been shown (Folch et al, 2001; Frossard et al, 2002a). When mice were treated with cerulein, TNF- $\alpha$ $\mathrm{Rl}$ concentrations increased in serum and in pancreatic and lung tissues (Fig. 6). Anti-MIP-2 antibody administration before or after cerulein significantly decreased TNF- $\alpha$ RI concentration in serum and tissue homogenates.

\section{Immunolocalization of MIP-2}

MIP-2 expression in pancreas and lungs was not detected in control mice but appeared in both organs after cerulein injections (Fig. 7). The expression was observed in macrophages in both pancreatic and lung tissues (Fig. 7, A and G) and in endothelial lining cells (Fig. 7, D to $\mathrm{E}$ and $\mathrm{J}$ to $\mathrm{K}$ ). The expression in the lungs was particularly high. Interestingly, MIP-2 was expressed only in pancreatic endothelial lining cells of venules (Fig. 7). No staining was observed in arterioles. The endothelial expression of MIP-2 was further confirmed by immunolocalization studies using antibody raised against von Willebrand factor (also known as factor VIII), which is expressed on any endothelial cells (Fig. 7, F and L).

\section{Discussion}

Intra-acinar cell activation of digestive enzymes within the pancreas is an early and premature event in the physiopathology of acute pancreatitis (Frossard and Pastor, 2002). Additionally, the ultimate severity of the disease results from nonacinar cell mechanisms, including the sequestration and activation of inflammatory cells within the pancreas, the local synthesis and release of proinflammatory mediators that transform a local injury into a systemic inflammatory response (Frossard et al, 2001b, 2002b; Norman, 1998; Steer and Meldolesi, 1988). Nonacinar cell phenomena include the local generation and release of proinflammatory factors that may spread from the pancreas to remote organs. Thus, acute lung injury is the most frequent complication that occurs in the course of acute pancreatitis (Ranson et al, 1973; Steer, 1989).

Leukocyte sequestration within injured tissues is a multistep process that begins with leukocyte activation, involves the adhesion of circulating and activated inflammatory cells to the microvascular endothelial cells (via leukocyte adhesion of proteins such as CD11/CD18 to endothelial molecules such as intercel- 
A



B

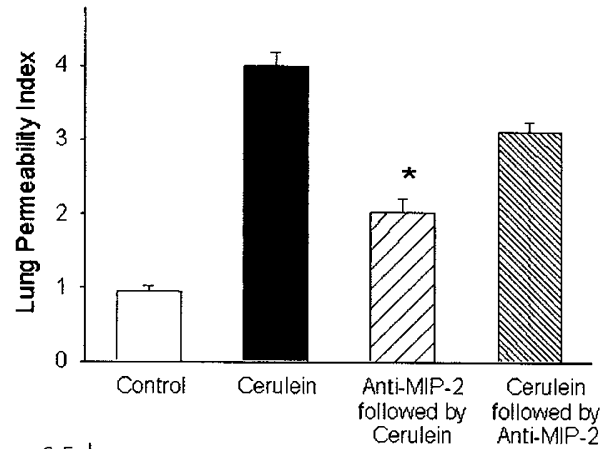

C

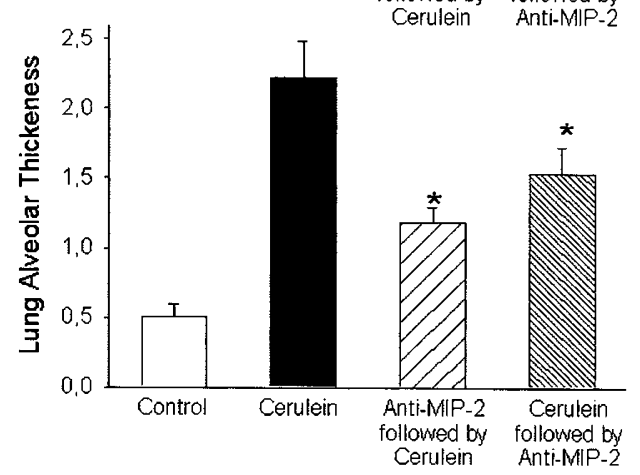

Figure 4.

Severity of pancreatitis-associated lung injury: lung water content $(A)$, lung permeability index $(B)$, and alveolar thickening $(C)$. Mice were injected with saline solution (open bars), cerulein and rat nonspecific IgG (solid bars), or anti-MIP-2 antibody and cerulein (light- and dark-hatched bars). Light-hatched bars: pretreatment with anti-MIP-2 antibody; dark-hatched bars: posttreatment with anti-MIP-2 antibody. Results are means \pm SEM. $n=8$ animals in each group. ${ }^{\star} p<0.05$ vs mice injected with cerulein and treated with rat nonspecific IgG.

lular adhesion molecule-1), and culminates in the transmigration of those cells across the endothelial barrier into the injured tissue (Springer, 1995). We recently showed that deficiency in intercellular adhesion molecule-1 and neutrophil depletion partially protect against cerulein-induced acute pancreatitis and pancreatitis-associated lung injury (Bhatia et al, 1998; Frossard et al, 1999).

Acute pancreatitis is identified as an inappropriate inflammatory response (Rinderknecht, 1988). The disease exhibits many of the features observed in the systemic inflammatory response syndrome, which is defined as a multiple organ failure after multiple trauma or burns (Roumen et al, 1992). Recent experimental evidence showed that cytokines and chemokines play a central role in the local progression of
A
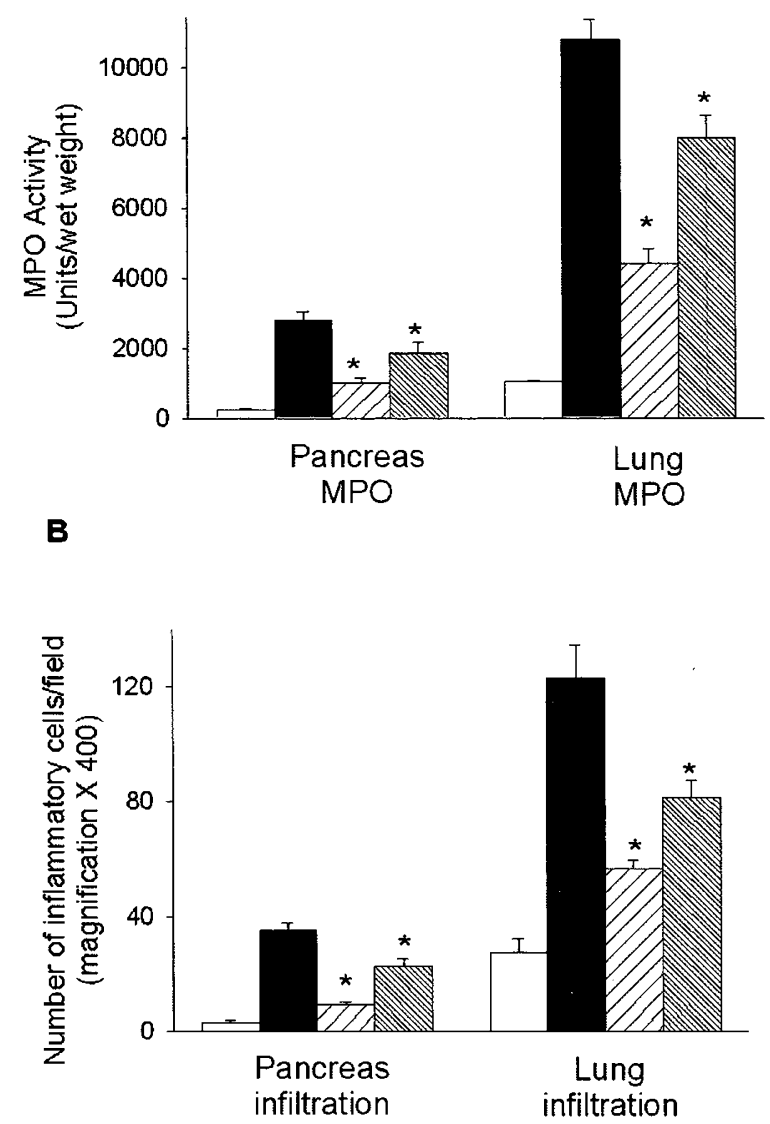

Figure 5.

Myeloperoxidase activity (MPO) (A) and number of inflammatory cells (B) in pancreas and lungs. Mice were injected with saline solution (open bars), cerulein and rat nonspecific IgG (solid bars), or anti-MIP-2 antibody and cerulein (light- and dark-hatched bars). Light-hatched bars: pretreatment with anti-MIP-2 antibody; dark-hatched bars: posttreatment with anti-MIP-2 antibody. $n=10$ in each group. ${ }^{*} p<0.05$ vs mice treated with cerulein and rat nonspecific $\lg G$.

acute pancreatitis and the occurrence of complications in remote organs (Bhatia et al, 2000, 2001; Frossard et al, 2002a; Norman et al, 1995, 1996a, 1996b; Pastor and Frossard, 2001; Van Laethem et al, 1995).

In the current study, we report that intrapancreatic concentrations of MIP-2 are markedly increased during severe secretagogue-induced acute pancreatitis and that the expression of MIP-2 in lungs is also increased. Interestingly, MIP-2 was expressed in pulmonary and pancreatic macrophages. Increased expression of MIP-2 has been found in cultured alveolar macrophages collected from rats with acute pancreatitis (Closa et al, 1999). MIP-2 is mainly located on endothelial lining cells. Previous study showed that stimulation of cultured endothelial cells with TNF- $\alpha$ increases the MIP-2 concentrations in supernatant (Otto et al, 2000). In this study, we have suggestive evidence that endothelial cells may produce MIP-2. However, the production of MIP-2 by endothelial cells was not specifically examined at the mRNA and protein levels. The MIP-2 protein could in fact be pro- 


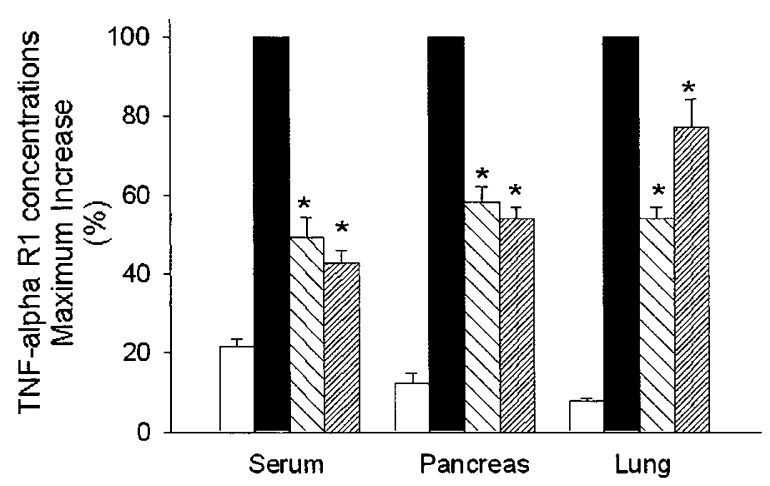

Figure 6.

TNF- $\alpha$ receptor I (TNF- $\alpha$-RI) concentrations in serum, pancreas, and lung are expressed as maximum increase (\%) to better delineate changes. Mice were injected with saline solution (open bars) or cerulein (solid bars, light-hatched bars, and dark-hatched bars). Light-hatched bars: pretreatment with antiMIP-2 antibody; dark-hatched bars: posttreatment with anti-MIP-2 antibody. Results are means \pm SEM. $n=7$ mice in each group. ${ }^{*} p<0.05$ vs mice injected with cerulein and rat nonspecific IgG.

duced at another site and sequestered later onto the endothelial cell or could be transcytosed onto the endothelial cell surface.

Pretreatment and posttreatment with anti-MIP-2 antibody in mice that received cerulein diminishes the MIP-2 concentrations in serum and in pancreas and lung homogenates. Consequently, the sequestration of leukocytes (as detected by MPO activity and the number of inflammatory cells) within the pancreas and lungs also decreased. Additionally, the severity of cerulein-induced pancreatitis and pancreatitisassociated lung injury was significantly reduced. These results are consistent with previous experiments. We recently studied the role of granulocytemacrophage CSF (GM-CSF) in cerulein-induced acute pancreatitis using GM-CSF knock-out mice, and our results suggest that GM-CSF plays a key role in coupling pancreatitis to lung injury. Indeed our data indicate that GM-CSF may act indirectly by regulating the release of other proinflammatory factors including MIP-2 (Frossard et al, 2002b). Ohtsuka et al (2001) demonstrated that, in small intestine epithelial cells, neutrophil recruitment increased in transgenic mice overexpressing MIP-2 and that the increased neutrophil recruitment was blocked by anti-MIP-2 antibody. In rat aspiration-induced lung injury, MIP-2 was also up-regulated and the increased lung MIP-2 concentrations were associated with neutrophil accumulation, whereas the blockade of MIP-2 at the onset of the disease improved lung injury (Shanley et al, 2000).

Interestingly, MIP-2 treatment also decreased the concentrations of TNF- $\alpha \mathrm{RI}$ in serum and tissue homogenates. Because TNF- $\alpha$ RI seemed to be correlated with the severity of acute pancreatitis in humans and experimental models (De Beaux and Fearon, 1996; de Beaux et al, 1996; Frossard et al, 2002a; Kaufmann et al, 1997), the decrease in TNF- $\alpha \mathrm{RI}$ is likely to contribute to the decreased severity of the disease. The fact that patients with high concentrations of TNF- $\alpha \mathrm{RI}$ and no detectable concentrations of free TNF- $\alpha$ develop multiple organ failure supports the concept that TNF- $\alpha \mathrm{RI}$ plays a proinflammatory role as opposed to a buffering effect in front of TNF- $\alpha$.

The partial protection obtained by anti-MIP-2 antibody suggests that the amount of antibody used in our model was insufficient for a full protection. This is suggested by the persistence of MIP-2 in serum and tissue homogenates after treatment with anti-MIP-2 antibody. Additionally, the chemokine system is characterized by an apparent redundancy of ligands and receptors, which complicates investigations of chemokine-regulated events. For example, although mice deficient in CCR1 receptor are protected against the development of pancreatitis-associated lung injury, the severity of pancreatitis was similar in wildtype mice, indicating that the CCR1 receptor is critical to extend pancreatic injury to remote organs (Gerard et al, 1997; Shanley et al, 2000).

In conclusion, our results show that MIP-2 plays a central role in the development of cerulein-induced acute pancreatitis and pancreatitis-associated lung injury. MIP-2 contributes to tissue injury by attracting leukocytes. Blocking MIP-2 either prophylactically or therapeutically reduced the severity of both pancreatitis and lung injury. Although full extrapolation to humans is difficult because the equivalence of MIP-2 and IL-8 or GRO- $\beta$ is speculative, targeting this family of chemokines by specific inhibitors may represent a major therapeutic tool.

\section{Materials and Methods}

\section{Animals}

All experiments were performed according to protocols approved by the Institutional Animal Care and the Veterinarian Office. Breeding pairs of BL6 mice were purchased from BRL Biological Research (Füllinsdorf, Switzerland) and were bred and housed in standard cages in a temperature-controlled $\left(23 \pm 2^{\circ} \mathrm{C}\right)$ environment with a 12-hour light/dark cycle. They were fed with standard laboratory chow, given water ad libitum, and randomly assigned to control or experimental groups.

\section{Induction of Pancreatitis}

Male mice (20-22 gm) were injected ip hourly for 10 hours (10 injections) with a supramaximally stimulating dose of cerulein (50 $\mu \mathrm{g} / \mathrm{kg}$ in $0.2 \mathrm{ml}$ of saline solution) to elicit a secretagogue-induced pancreatitis. Cerulein, the analog of the pancreatic secretagogue cholecystokinin, was purchased from Research Plus (Bayonne, New Jersey). Control mice received comparable injections of saline solution. One hour after the final injection, mice were killed by a lethal ip injection of pentobarbital.

\section{Anti-MIP-2 Antibody Treatments}

For pharmacologic blockade of MIP-2, the rat monoclonal anti-mouse MIP-2 lgG (R\&D, Abingdon, United Kingdom) was injected 1 hour before or 2 hours after the start of cerulein administration. Control mice were 

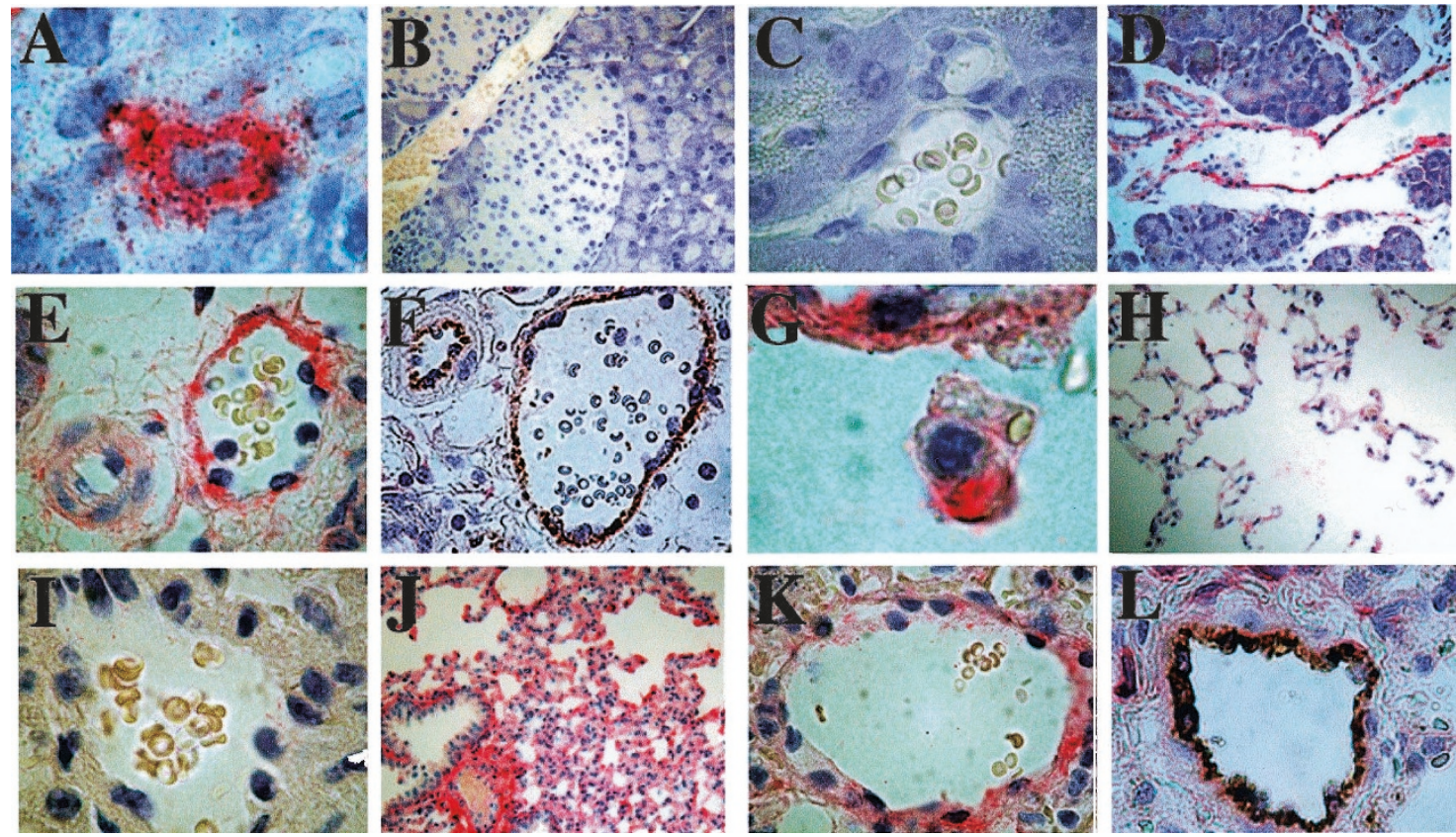

Figure 7.

MIP-2 immunolocalization in pancreas ( $A$ to $E$ ) and lungs ( $G$ to K). Mice had 10 ip injections of saline solution (B, C, H, and I) or cerulein (A, D to $F$, G, and $J$ to L). MIP-2 is stained in red. In control mice, no MIP-2 was expressed either in pancreas ( $B$ and $C)$ or lungs $(H$ and I). Low magnification $(\times 400, B$ and $H)$ and high magnification $(\times 800, C$ and I). After cerulein injection, MIP-2 was expressed in endothelial lining cells in both pancreas $(\mathrm{D}$ and $\mathrm{E})$ and lung tissues $(\mathrm{J}$ and $\mathrm{K})$. Low magnification $(\times 400, D$ and J). High magnification $(\times 800, E$ and $K)$. Pancreatic $(A)$ and lung alveolar $(G)$ macrophages were also stained for MIP-2 in mice injected with cerulein (magnification $\times 1000$ ). These results are representative of at least three animals. Immunolocalization of von Willebrand factor was used to support the endothelial expression of MIP-2: von Willebrand factor appears in brown in endothelial lining cells in pancreas (F) and lung (L) (magnification $\times 1000)$.

injected with the rat nonspecific IgG. Treatments were injected via the tail (100 $\mu \mathrm{g}$ of anti MIP-2 antibody in $0.2 \mathrm{ml}$ of saline solution). This dose was extrapolated from previous publications in which 0.8 to $1.5 \mathrm{mg}$ in each rat (300 $\mathrm{gm}$ body weight) was sufficient to demonstrate a significant protection in a different experimental model (Ohtsuka et al, 2001; Shanley et al, 2000).

\section{Quantification of Cerulein-Induced Injuries}

At the time of death, blood was withdrawn from the heart and centrifuged for 10 minutes at $3000 \mathrm{rpm}$ (rounds per minute; the serum was kept at $-80^{\circ} \mathrm{C}$ until assayed. Serum amylase activity was measured as described by Pierre et al (1972) using 4,6-ethylidene (G1)-pnitrophenyl (G1)- $\alpha$ D-malto-heptoside (Sigma Chemical Company, St. Louis, Missouri) as substrate. Blood and pancreatic tissue were processed as described previously (Frossard et al, 1999, 2001a). Briefly, the pancreas was rapidly removed and divided in several parts. One part was used to quantitate the extent of pancreatic edema by measuring tissue water content. Pancreatic tissue was weighed before and after desiccation at $95^{\circ} \mathrm{C}$ during 24 hours. The difference between the wet and dry tissue weights was calculated and expressed as a percent of the tissue wet weight. The other parts of pancreatic tissues were frozen in liquid nitrogen for later analysis.

Neutrophil sequestration within the pancreas was detected by measuring tissue MPO activity (Frossard et al, 2001b). For these measurements, tissue samples were thawed, homogenized in $1 \mathrm{ml}$ of $20 \mathrm{~mm}$ phosphate buffer $(\mathrm{pH} 7.4)$, centrifuged $(10,000 \times g, 10$ minutes), and the resulting pellet was resuspended in $50 \mathrm{~mm}$ phosphate buffer $(\mathrm{pH} 6.0$ ) containing $0.5 \%$ hexadecylmethylammonium bromide. The suspensions were subjected to four cycles of freezing and thawing and then sonicated. The samples were centrifuged $(10,000 \times g, 5$ minutes), and the supernatants were used for MPO assay activity. The reaction mixture consisted of this extracted enzyme, $1.6 \mathrm{~mm}$ tetramethylbenzidine (Sigma, Switzerland), $80 \mathrm{~mm}$ sodium phosphate buffer (pH 5.4), and $0.3 \mathrm{~mm}$ hydrogen peroxide (Sigma, Switzerland). This mixture was incubated at $37^{\circ} \mathrm{C}$ for 2 minutes, and the absorbance was read by a Roche autoanalyzer. MPO activity was expressed as a function of tissue wet weight. The numbers of inflammatory cells that infiltrated the pancreas and the lung were visually counted on representative stained pancreatic and lung sections using $\times 400$ magnification.

Pulmonary microvascular permeability was evaluated by quantitating the leakage of intravenously administered FITC-labeled bovine albumin $(0.5 \mathrm{mg} / \mathrm{kg}$ in $0.2 \mathrm{ml}$ ) into the bronchoalveolar space (Frossard et al, 2002a). Immediately after death, the trachea was exposed and the lungs were lavaged three times with $1 \mathrm{ml}$ of saline solution. The lavage fluid was collected, and FITC fluorescence was measured in the lavage fluid and serum using a Hitachi spectrofluorophotometer (excitation $=494 \mathrm{~nm}$; emission $520 \mathrm{~nm}$ ). The ratio of fluorescence between bronchoalveolar lavage fluid 
and blood was calculated and expressed as the permeability index.

\section{MIP-2 and TNF- $\alpha$ RI Measurements}

MIP-2 and TNF- $\alpha$ RI were quantitated in serum, pancreas, and lung using commercially available ELISA kits (R\&D). Freshly isolated tissues were homogenized in 1.5 $\mathrm{ml}$ of phosphate buffer $(20 \mathrm{mmol} / \mathrm{L}, \mathrm{pH} 7.4)$. After centrifugation $\left(14,000 \times g\right.$ for 5 minutes at $\left.4^{\circ} \mathrm{C}\right)$, MIP-2 and TNF- $\alpha$ R1 concentrations were measured in the supernatant according to the manufacturer's recommendations and expressed as micrograms of MIP-2 or TNF- $\alpha$ $\mathrm{RI}$ per microgram of protein in the sample. MIP-2 values and TNF- $\alpha \mathrm{RI}$ are given as the percent maximum increase to better delineate changes. The concentrations for the maximal level of expression of MIP-2 and TNF- $\alpha$ $\mathrm{RI}$ in pancreatitis animals were as follows: serum MIP-2, $309.3 \pm 40$ pg/ml; pancreatic MIP-2, $190.8 \pm 32$ pg/mg protein; lung MIP-2, $243.4 \pm 36 \mathrm{pg} / \mathrm{mg}$ protein; serum TNF- $\alpha$ Rl, $2004 \pm 40$ pg/ml; pancreatic TNF- $\alpha$ Rl, 714.2 \pm 79 pg/mg protein; and lung TNF- $\alpha$ Rl, $1201.2 \pm 90$ $\mathrm{pg} / \mathrm{mg}$ protein.

\section{Morphology}

At the time of death, sections of the pancreas were rapidly removed, fixed in $4 \%$ neutral phosphatebuffered formalin, embedded in paraffin, and sectioned $(5 \mu \mathrm{m})$. After staining with hematoxylin and eosin, sections were examined by two morphologists who were not aware of the sample identity. The extent of acinar cell necrosis was quantitated by computerassisted morphometry and expressed as a percentage of total acinar tissue (Frossard et al, 1999). Acinar cell necrosis was defined as the destruction of architecture with a loss of integrity of all elements of the acini in combination with inflammation. After exclusion of nonacinar cells (islets of Langerhans and perivascular and periductal adventitial tissue), the amount of acinar injury/necrosis and the extent of the interacinar space containing inflammatory cells were morphometrically quantitated using a computerized image analysis video unit (Zeiss Camera, Zeiss, Bern, Switzerland).

For pulmonary morphology, a polyvinyl catheter was inserted into the trachea and used to instill $4 \%$ neutral buffered formalin into the lungs at a hydrostatic pressure of $30 \mathrm{~cm} \mathrm{H}_{2} \mathrm{O}$. Portions of the formalindistended lungs were harvested, fixed, paraffinembedded, sectioned $(5 \mu \mathrm{m})$, stained, and examined by two morphologists who were not aware of the sample identity. The extent of alveolar-capillary membrane thickening was visually estimated according to the following score attributed to each field: zero represented a normal lung and four represented the more severe injury as recently described by our group (Frossard et al, 2002a, 2002b).

\section{Immunolocalization of MIP-2}

Immunolocalization of MIP-2 in pancreatic and lung tissues collected from mice injected with saline solution or cerulein was studied by conventional light micros- copy. Samples of tissues were fixed in 4\% neutral phosphate-buffered formalin, embedded in paraffin, and sectioned $(5 \mu \mathrm{m})$. Endogenous peroxidase activity was quenched by treating the sections with $3 \%$ hydrogen peroxide for 10 minutes, and nonspecific binding was blocked by incubating sections in 1\% BSA in PBS for 30 minutes followed by incubation in avidin and biotin blocking solutions for 15 minutes each, with PBS rinses in between. Sections were then incubated for 1 hour with the primary antibody (rat monoclonal anti-mouse MIP-2 lgG) diluted in BSA-PBS. Control sections were incubated in BSA-PBS without the first antibody and showed no immunostaining. After rinsing with PBS, the sections were sequentially treated with biotinylated secondary antibody (1:200 anti-rat lgG in BSA-PBS) for 30 minutes and Vecta $A B C$ reagent for 30 minutes. Sections were rinsed with PBS between each step. Sections were subsequently counterstained with methyl green $(1 \%$ in $0.1 \mathrm{~m}$ sodium acetate, $\mathrm{pH} 4.0$ ) for 10 minutes, rinsed in distilled water and butanol (three times) each, cleared in xylene, and coverslipped with Permount. The antigenantibody complex was visualized using the alkaline phosphatase complex method (Dako, Glostrup, Denmark). Images were collected with a Zeiss Camera and processed with the Coll view image software. The same procedure was used for the detection of the von Willebrand factor with the following changes: 1-hour incubation with polyclonal rabbit anti human von Willebrand factor. After rinsing with PBS, the sections were sequentially treated with a swan anti-rabbit antibody as a secondary antibody (1:750 in BSA-PBS) for 30 minutes and Vecta $A B C$ reagent for 30 minutes as recommended by the supplier. Sections were rinsed with PBS between each step.

\section{Analysis of Data}

Results represent mean \pm SEM values obtained from multiple determinations in three or more separate experiments. In all figures, vertical bars denote SEM values and the absence of such bars indicates that the SEM is too small to be illustrated. The significance of changes was evaluated using Student's $t$ test when data consisted of only two groups or by ANOVA when three or more groups were compared. A $p$ value $\leq$ 0.05 was considered significant.

\section{References}

Baggiolini M, Dewald B, and Moser B (1997). Human chemokines: An update. Annu Rev Immunol 15:675-676.

Bhatia M, Brady M, Zagorski J, Christmas S, Campbell F, Neoptolemos J, and Slavin J (2000). Treatment with neutralizing antibody against cytokine induced neutrophil chemoattractant (CINC) protects rats against acute pancreatitis associated lung injury. Gut 47:838-844.

Bhatia M, Saluja A, Singh V, Frossard JL, Lee H, Bhagat L, Gerard C, and Steer M (2001). Complement factor C5a exerts an anti-inflammatory effect in acute pancreatitis and associated lung injury. Am J Physiol 280:974-978.

Bhatia M, Saluja AK, Hofbauer B, Lee HS, Frossard JL, and Steer ML (1998). The effects of neutrophil depletion on a 
completely noninvasive model of acute pancreatitisassociated lung injury. Int J Pancreatol 24:77-83.

Closa D, Sabater L, Fernandez-Cruz L, Prats N, Gelpi E, and Rosello-Catafau J (1999). Activation of alveolar macrophages in lung injury associated with experimental acute pancreatitis is mediated by the liver. Ann Surg 229:230-236.

De Beaux AC and Fearon KC (1996). Circulating endotoxin, tumor necrosis factor-alpha, and their natural antagonists in the pathophysiology of acute pancreatitis. Scand J Gastroenterol Suppl 219:43-46.

de Beaux AC, Goldie AS, Ross JA, Carter DC, and Fearon KC (1996). Serum concentrations of inflammatory mediators related to organ failure in patients with acute pancreatitis. Br J Surg 83:349-353.

Folch E, Serrano A, Sabater L, Gelpi E, Rosello-Catafau J, and Closa D (2001). Soluble receptors released during acute pancreatitis interfere with the detection of tumor necrosis factor-alpha. Crit Care Med 29:1023-1026.

Frossard JL, Hadengue A, and Pastor C (2001a). New serum markers for the detection of severe acute pancreatitis in humans. Am J Respir Crit Care Med 164:162-170.

Frossard JL, Hadengue A, Spahr L, Morel P, and Pastor C (2002a). Natural history of long-term lung injury in mouse experimental pancreatitis. Crit Care Med 30:1541-1546.

Frossard JL, Kwak B, Chanson M, Morel P, Hadengue A, and Mach F (2001b). CD40L deficient mice are protected against cerulein-induced acute pancreatitis and pancreatitisassociated lung injury. Gastroenterology 121:184-194.

Frossard JL and Pastor C (2002). Experimental acute pancreatitis: New insights into the pathophysiology. Front Biosci 7:275-287.

Frossard JL, Saluja A, Bhagat L, Lee H, Bhatia M, Hofbauer B, and Steer M (1999). The role of intercellular adhesion molecule 1 and neutrophils in acute pancreatitis and pancreatitisassociated lung injury. Gastroenterology 116:694-701.

Frossard JL, Saluja A, Mach N, Lee H, Bhagat L, Hadengue A, Rubbia-Brandt L, Dranoff G, and Steer M (2002b). In vivo evidence for the role of GM-CSF as a mediator in acute pancreatitis-associated lung injury. Am J Physiol Lung Cell Mol Physiol 283:541-548.

Gerard C, Frossard JL, Bhatia M, Saluja A, Gerard N, Lu B, and Steer M (1997). Targeted disruption of the betachemokine receptor CCR1 protects against pancreatitisassociated lung injury. J Clin Invest 100:2022-2027.

Grady T, Liang P, Ernst S, and Logsdon C (1997). Chemokine gene expression in rat pancreatic acinar cells is an early event associated with acute pancreatitis. Gastroenterology 113:1966-1975.

Gross V, Andreesen R, Leser H, Ceska M, Liehl E, Lausen M, Farthmann E, and Scholmerich J (1992). Interleukin-8 and neutrophil activation in acute pancreatitis. Eur $\mathrm{J}$ Clin Invest 22:200-203.

Hang L, Haraoka M, Agace W, Leffler H, Burdick M, Strieter $R$, and Svanborg C (1999). Macrophage inflammatory protein-2 is required for neutrophil passage across the epithelial barrier of the infected urinary tract. J Immunol 162: 3037-3044.

Kaufmann P, Tilz GP, Lueger A, and Demel U (1997). Elevated plasma levels of soluble tumor necrosis factor receptor
(sTNFRp60) reflect severity of acute pancreatitis. Intensive Care Med 23:841-848.

Murphy P, Baggiolini M, Charo I, Hebert C, Horuk R, Matsushima K, Miller L, Oppenheim J, and Power C (2000). International union of pharmacology. XXII. Nomenclature for chemokine receptors. Pharmacol Rev 52:145-176.

Norman JG (1998). The role of cytokines in the pathogenesis of acute pancreatitis. Am J Surg 175:76-83.

Norman JG, Franz M, Messina J, Riker A, Fabri P, Rosemurgy A, and Gower W (1995). Interleukin-1 receptor antagonist decreases severity of experimental acute pancreatitis. Surgery 117:648-655.

Norman JG, Fink GW, Messina J, Carter G, and Franz MG (1996a). Timing of tumor necrosis factor antagonism is critical in determining outcome in murine lethal acute pancreatitis. Surgery 120:515-521.

Norman JG, Fink GW, Sexton C, and Carter G (1996b). Transgenic animals demonstrate a role for the IL-1 receptor in regulating IL-1beta gene expression at steady-state and during the systemic stress induced by acute pancreatitis. J Surg Res 63:231-236.

Ohtsuka Y, Lee J, Stamm S, and Sanderson I (2001). MIP-2 secreted by epithelial cells increases neutrophil and lymphocyte recruitment in the mouse intestine. Gut 49:526-533.

Otto V, Heinzel-Pleines U, Gloor S, Trentz O, Kossman T, and Morganti-Kossman M (2000). sICAM-1 and TNF-alpha induce MIP-2 with distinct kinetics in astrocytes and brain microvascular endothelial cells. J Neurosci Res 15:733-742.

Pastor C and Frossard JL (2001). Are genetically modified mice useful for the understanding of acute pancreatitis? FASEB J 15:893-897.

Pierre K, Tung K, and Nadj H (1972). A new enzymatic kinetic method for determination of amylase. Clin Chem 22:1219.

Ranson JH, Roses DF, and Fink SD (1973). Early respiratory insufficiency in acute pancreatitis. Ann Surg 178:75-79.

Rinderknecht H (1988). Fatal pancreatitis: A consequence of excessive leukocyte stimulation? Int J Pancreatol 33:105-112.

Roumen R, Schers T, de Boer H, and Goris R (1992). Scoring systems for predicting outcome in acute hemorrhagic necrotizing pancreatitis. Eur J Surg 158:167-171.

Shanley T, Davidson B, Nader N, Bless N, Vasi N, Ward P, Johnson K, and Knight P (2000). Role of macrophage inflammatory protein-2 in aspiration-induced lung injury. Crit Care Med 28:2437-2444.

Springer T (1995). Traffic signals on endothelium for lymphocyte recirculation and leukocyte emigration. Annu Rev Physiol 57:827-872.

Steer ML (1989). Classification and pathogenesis of pancreatitis. Surg Clin North Am 69:467-480.

Steer ML and Meldolesi J (1988). Pathogenesis of acute pancreatitis. Annu Rev Med 39:95-105.

Steinberg W and Tenner S (1994). Acute pancreatitis. N Engl J Med 330:1198-1210.

Van Laethem J, Marchant A, Delvaux A, Goldman M, Robberecht P, Velu T, and Deviere J (1995). Interleukin 10 prevents necrosis in murine experimental acute pancreatitis. Gastroenterology 108:1917-1922. 